\title{
Tomato Fruit Chilling Tolerance in Relation to Internal Atmosphere after Return to Ambient Temperature
}

\author{
M. Bergevin, G.P. L'Heureux, and C. Willemot ${ }^{1}$ \\ Department of Food Science and Technology, Université Laval, Qué. G1K \\ 7P4, Canada
}

Additional index words. Lycopersicon esculentum, $\mathrm{CO}_{2}$

\begin{abstract}
Mature-green 'Vedette' tomato (Lycopersicon esculentum Mill.) fruit were stored with $(+\mathrm{P})$ or without $(-\mathrm{P})$ peduncles at $1 \mathrm{C}$. During storage and after return to ambient temperature, pigment content and electrolyte leakage of pericarp tissue and fruit internal atmosphere composition were monitored. The $+P$ fruit showed severe chilling injury (CI) symptoms-shriveling and brown discoloration of the surface-on transfer to $20 \mathrm{C}$ after at least 8 days of exposure to low temperature. The chilling-injured fruit did not ripen normally; i.e., pigmentation did not change at $20 \mathrm{C}$. The $-P$ fruit were largely unaffected and ripened normally at $20 \mathrm{C}$. Severely injured tomatoes showed an apparent decrease in electrolyte leakage after transfer to ambient temperature. The $\mathrm{CO}$, content of the -P fruit internal atmosphere was significantly lower than in $+P$ tomatoes after return to $20 \mathrm{C}$. The peduncle scar has a greater permeability to gases than the skin and facilitates gas exchange with the external atmosphere. The accumulation of $\mathrm{CO}$, in the internal atmosphere of the chilled $+P$ fruit after transfer to $20 \mathrm{C}$ apparently promoted CI symptom development.
\end{abstract}

Mature-green tomato fruit are sensitive to chilling when stored at temperatures below 13C(Autio and Bramlage, 1986; Wang, 1989). The main chilling-injury (CI) symptoms are abnormal ripening and increased postharvest decay (Autio and Bramlage, 1986; Cheng and Shewfelt, 1988).

Controlled or modified atmospheres have been used to increase tomato storage life at nonchilling temperatures (Buescher, 1979; Geeson et al., 1985; Nakhasi et al., 1991; Parsons et al., 1970; Salunkhe and Wu, 1973). These storage techniques also have been used in conjunction with low temperature. In some studies, modifying the storage atmosphere failed to alleviate tomato CI (Forney and Lipton, 1990; Kader and Morris, 1975; Tomkins, 1963), while in other studies, chilling symptoms were delayed orreduced (Brown et al., 1989; Hobson, 1987).

The present report stems from our observation that mature-green tomato fruit without peduncles (-P) stored at low temperature showed less severe CI symptoms than fruit with the peduncle still attached $(+\mathrm{P})$ after return to ambient temperature. As a preliminary study of using modified atmospheres to alleviate CI, the influence of fruit internal atmosphere composition on CI symptom develop-

Received for publication 13 Sept. 1992. Accepted for publication 23 Oct. 1992. This research was supported by Natural Sciences and Engineering Research Council of Canada (NSERC) strategic grant no. STR0114645. M.B. was a recipient of an NSERC postgraduate fellowship. Contribution no. 49 of the Centre de Recherche en Horticulture, Université Laval; contribution no. 266 of the Food Research and Development Center (FRDC), Agriculture Canada, Saint-Hyacinthe.

'Research Scientist, FRDC; to whom reprint requests should be addressed at Université Laval. ment was examined in mature-green $+\mathrm{P}$ or- $\mathrm{P}$ tomatoes stored at $1 \mathrm{C}$ and subsequently returned to 20C.

Mature-green (U.S. Dept. of Agriculture Marketing Service, 1976), greenhouse-grown 'Vedette' tomatoes were harvested from a local farm. The fruit were selected for uniformity in size and absence of lesions, and their surfaces were sanitized in a $1 \%(\mathrm{v} / \mathrm{v})$ hypochlorite solution. The tomatoes were divided into two lots: the peduncles and calyxes were removed from one lot (-P), while the other lot was left intact $(+\mathrm{P})$. The fruit were stored in darkness at $1 \mathrm{C}$ under a continuous flow of humidified air at $85 \%$ relative humidity. Three fruit from each lot were analyzed on day 0,6 , 8 , and 21 for pericarp pigment content, electrolyte leakage, and internal atmosphere composition. After 6, 8, and 10 days of chilling, three fruit were returned to $20 \mathrm{C}$ and analyzed after 7 days. Some unchilled fruit were kept at 20C to measure the internal atmosphere during normal ripening at the mature-green, turning, and red-ripe stages.

The fruit were visually evaluated for CI symptoms, including surface pitting, shriveling, skin discoloration, and uneven ripening.

Ripening was assessed based on pigment content. Seven-millimeter-diameter disks were sampled from the outer pericarp tissue with a cork borer. Two grams of freshly excised disks was homogenized in $10 \mathrm{ml}$ of 60 hexane : 40 acetone (v/v) for $2 \mathrm{~min}$ at $9500 \mathrm{rpm}$ using an Ultra-turrax homogenizer (model T 25; Janke and Kunkel, Hohenstaufen, Germany). The homogenate was vacuum-filtered. The residue was rinsed twice with $10 \mathrm{ml}$ of extraction solvent, and the combined extracts were centrifuged for $5 \mathrm{~min}$ at $500 \times \mathrm{g}$. The upper phase was collected and evaporated to dryness under $\mathrm{N}$, . The residue was dissolved in $5 \mathrm{ml}$ of chloroform, and the optical density was measured (model 8451A Diode Array; Hewlett Packard, Mississauga, Ont., Canada) at 480 $\mathrm{nm}$ for carotenoids, mainly lycopene, and at $664 \mathrm{~nm}$ for chlorophyll. Pure pigment solutions (Sigma, St. Louis) were used to prepare standard curves.

Electrolyte leakage was determined as an indirect measure of membrane damage and CI. About $2 \mathrm{~g}$ of freshly excised disks from three fruit per treatment was placed in $100 \mathrm{ml}$ $0.4 \mathrm{M}$ mannitol and incubated at $25 \mathrm{C}$ for $4 \mathrm{~h}$. Electrical conductivity of the bathing solution was determined at $25 \mathrm{C}$ using a conductance meter (model 35; YSI, Yellow Springs, Ohio) after incubation and again after autoclaving at $121 \mathrm{C}$ for $30 \mathrm{~min}$ to liberate all electrolytes. Electrolyte leakage was expressed as percentage of total electrolytes.

To determine the internal atmosphere, fruit were immersed in water, and $1 \mathrm{ml}$ of internal atmosphere was removed with a syringe. The peduncles of the intact fruit were removed under water-just before sampling. Carbon dioxide, $\mathrm{O}_{2}$, and $\mathrm{N}_{2}$ were determined by a gas chromatograph (GC) (model 8500; Perkin Elmer, Mississauga, Ont., Canada) fitted with a thermal conductivity detector and two columns: Porapak Q $(90 \times 0.3 \mathrm{~cm}, 80 / 100 \mathrm{mesh})$ and molecular sieve $(180 \times 0.3 \mathrm{~cm}, 8 \mathrm{O} / 100$ mesh; Supelco, Oakville, Ont., Canada). The oven was isothermal at $60 \mathrm{C}$.

Two experiments were carried out during this study and they yielded similar results. The data from the first experiment are reported. Data are means \pm SD from triplicate measurements for each treatment. Each datum was the average of three determinations per fruit for electrolyte leakage and internal atmosphere and of two pigment determinations.

Tomatoes developed only slight surface pitting after 21 days of low-temperature storage. Fruit did not ripen during chilling at $1 \mathrm{C}$, as assessed by the absence of red pigment. No CI symptoms developed during 7 days at 20C after 6 days of chilling, and the fruit began to ripen normally. After 8 and 10 days of chilling, however, severe CI symptoms developed on $+\mathrm{P}$ fruit, while $-\mathrm{P}$ fruit were largely unaffected. After 7 days at 20C following 8 and 10 days of chilling, $+\mathrm{P}$ tomatoes showed no sign of ripening and displayed severe shriveling and brown skin discoloration. One-third of the -P fruit was slightly affected by chilling and the rest ripened normally. A preliminary screening of tomato cultivars indicated that the difference in response to chilling between $+\mathrm{P}$ and-P 'Vedette' fruit may not apply to all cultivars.

Although chlorophyll content was reduced by $\approx 50 \%$ after 21 days of chilling at $1 \mathrm{C}$, no lycopene accumulated during this period (Fig. 1). This result indicates that no significant ripening occurred at low temperature. After 6 days of chilling, transferring the fruit to ambient temperature led to lycopene accumulation and chlorophyll depletion in $+\mathrm{P}$ and $-\mathrm{P}$ fruit. Only-P tomatoes accumulated lycopene after transfer to $20 \mathrm{C}$ following 8 and 10 days of chilling. 


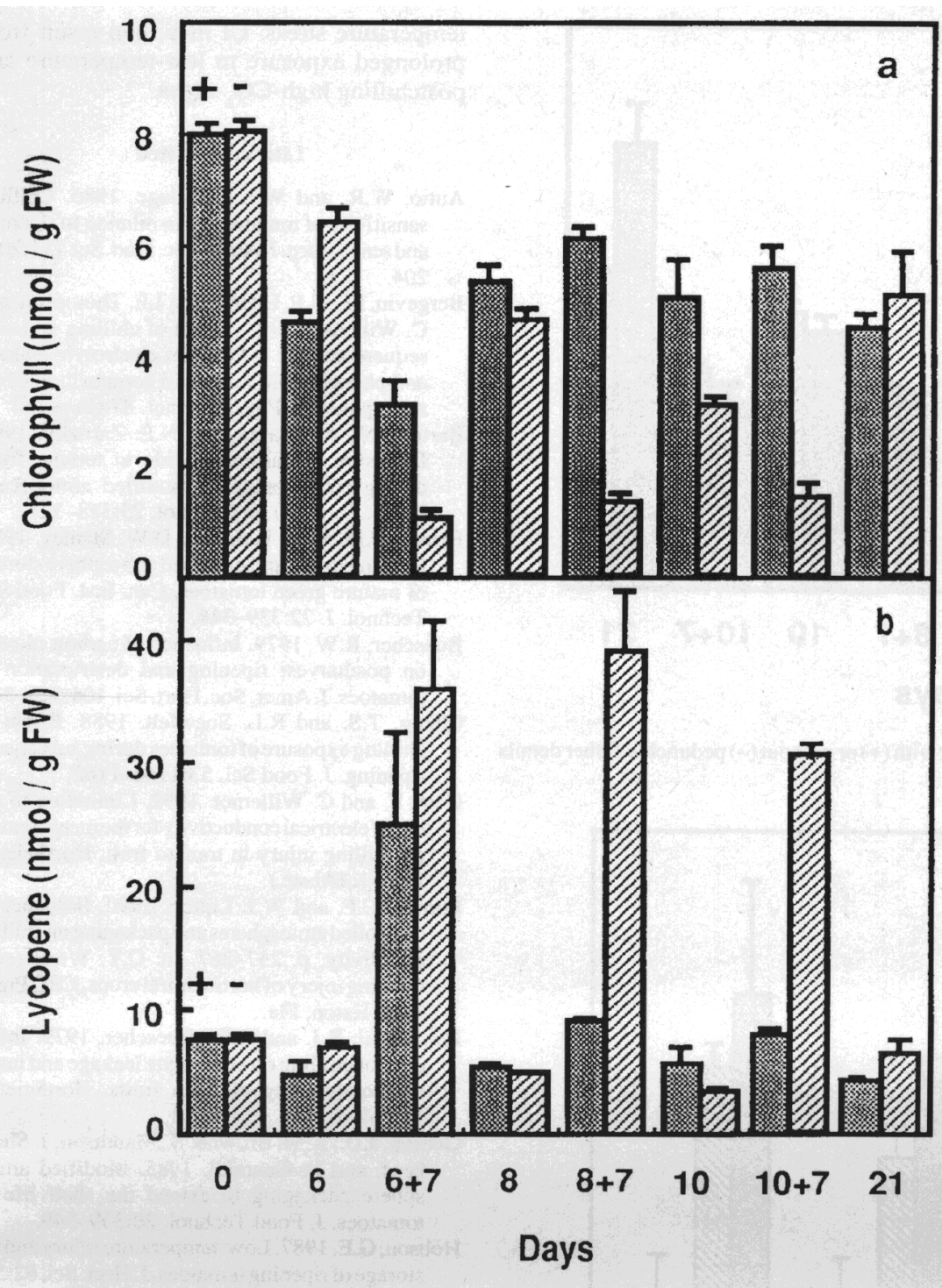

Fig. 1. Pigment contents of pericarp tissue of fruit with $(+)$ or without (-) peduncles during storage at $1 \mathrm{C}$ and after transfer to $20 \mathrm{C}$ for 7 days following $6(6+7), 8$, or 10 days of chilling. (a) Chlorophyll, (b) lycopene. Vertical bars indicate SD.

Electrolyte leakage from the pericarp tissue progressively increased during storage at 1C (Fig. 2). The increase was similar for $+\mathrm{P}$ or -P fruit. Only after 21 days of chilling did electrolyte leakage reach a higher value for $+\mathrm{P}$ tomatoes. After transfer to $20 \mathrm{C}$, electrolyte leakage decreased for both fruit lots. The $+\mathrm{P}$ fruit electrical conductivity during storage at ambient temperature consistently returned to the values measured at day 0 before chilling. The -P fruit conductivity never reached this low value after storage for 7 days at $20 \mathrm{C}$ following 6,8 , or 10 days of chilling.

The internal atmosphere $\mathrm{CO}_{2}$ content decreased during low-temperature storage, from $2.4 \%$ on day 0 to $\approx 1.0 \%$ at day 21 (Fig. 3). At each sampling date, $\mathrm{CO}_{2}$ content was lower in $-\mathrm{P}$ than in $+\mathrm{P}$ fruit. After transfer to $20 \mathrm{C}, \mathrm{CO}_{2}$ content increased in all fruit but to a greater extent in $+\mathrm{P}$ fruit, which developed severe $\mathrm{CI}$ symptoms. The increase in $\mathrm{CO}_{2}$ content during storage at $20 \mathrm{C}$ in-P fruit became greater with length of exposure to low temperature. After
10 days of chilling, $\mathrm{CO}_{2}$ content reached almost the same level as that in $+\mathrm{P}$ fruit. Fruit $0_{2}$ content was affected little by exposure to low temperature and subsequent storage at $20 \mathrm{C}$, and remained between $16 \%$ and $21 \%$. Normal fruit ripening at ambient temperature had little influence on internal atmosphere composition (Table 1). Fruit contained a slightly lower $\mathrm{CO}_{2}$ content at the red-ripe than at the mature-green stage. The $+\mathrm{P}$ fruit accumulated some $\mathrm{CO}_{2}$ at the turning stage.

The results of this study suggest a link between tomato internal atmosphere composition after fruit were returned to ambient temperature and fruit response to chilling, as assessed by ripening and electrolyte leakage. After exposure to low temperature, differences in internal atmosphere composition of $+\mathrm{P}$ and -P fruit became apparent mainly during storage at 20C, when differences in ripening, electrolyte leakage, and CI symptoms developed between $+\mathrm{P}$ and $-\mathrm{P}$ fruit. The $+\mathrm{P}$ tomatoes that accumulated $\mathrm{CO}_{2}$ during postchilling
Table 1. Content (percent) of $\mathrm{CO}_{2}$ in the internal atmosphere of nonchilled tomato fruit, with $(+\mathrm{P})$ or without $(-\mathrm{P})$ peduncles, during normal ripening at $20 \mathrm{C}$.

\begin{tabular}{lcc}
\hline \multirow{2}{*}{$\begin{array}{l}\text { Ripening } \\
\text { stage }\end{array}$} & \multicolumn{2}{c}{$\mathrm{CO}_{2}$ content $(\%)$} \\
\cline { 2 - 3 } Mature-green & $+\mathrm{P}$ & $-\mathrm{P}$ \\
Turning & $1.82 \pm 0.56$ & $1.82 \pm 0.56$ \\
Red-ripe & $2.39 \pm 0.52$ & $1.06 \pm 0.14$ \\
\hline
\end{tabular}

storage at 20C lost their ability to ripen after 8 days of chilling. Chilled-P fruit accumulated less $\mathrm{CO}_{2}$ at $20 \mathrm{C}$ and maintained their ability to ripen, even after 10 days of chilling.

The reduction in $\mathrm{CO}_{2}$ during low-temperature storage (Fig. 3) probably reflects a reduced fruit respiration rate at $1 \mathrm{C}$. The increase in $\mathrm{CO}_{2}$ in $+\mathrm{P}$ fruit internal atmosphere from $2.4 \%$ to $>4 \%$ during storage at $20 \mathrm{C}$ following chilling may result from an enhanced respiration rate, as reported for many chillingsensitive crops, including tomatoes (Lyons and Breidenbach, 1990), following low-temperature treatment. The peduncle scar, which is much more permeable to gases than the skin (Bertola et al., 1990), allowed more $\mathrm{CO}_{2}$ to escape from the $-\mathrm{P}$ tomatoes, and the $\mathrm{CO}_{2}$ content in these fruit remained $<3 \%$ after 6 and 8 days of chilling. The increasing accumulation of $\mathrm{CO}$, in $-\mathrm{P}$ fruit at $20 \mathrm{C}$ with longer exposure to chilling temperatures (Fig. 3) may reflect increasing CI.

The accumulation of $\mathrm{CO}$, in the internal atmosphere of $+\mathrm{P}$ fruit after they were returned to ambient temperature may result from a stress-induced stimulation of respiration and from an increased resistance of the tissues to $\mathrm{CO}_{2}$ diffusion out of the fruit. The increased tissue resistance to gas diffusion would follow intercellular space flooding due to the damaged membranes' enhanced permeability to water.

Although electrolyte leakage-an indirect measure of membrane damage-increased slightly with chilling time, it correlated neither with internal $\mathrm{CO}_{2}$ content nor with $\mathrm{CI}$ symptoms. No difference in electrical conductivity was noticed between $+\mathrm{P}$ or $-\mathrm{P}$ fruit during chilling, except after 21 days, although $+\mathrm{P}$ fruit consistently contained higher $\mathrm{CO}_{2}$ concentrations. The fruit chilled for 21 days showed the greatest electrolyte leakage but contained the least $\mathrm{CO}_{2}$.

After 10 days of chilling and 7 days at 20C, -P fruit had accumulated $>4 \% \mathrm{CO}_{2}$ in their internal atmosphere-almost as much as $+\mathrm{P}$ fruit-but showed relatively little electrolyte leakage and no CI symptoms. The absence of severe symptoms may reflect slower $\mathrm{CO}_{2}$ accumulation in -P fruit and, therefore, shorter exposure to high $\mathrm{CO}_{2}$.

Chilled fruit electrolyte leakage values decreased during subsequent storage at 20C, while $\mathrm{CO}$, accumulated and $\mathrm{CI}$ symptoms developed. This apparent decrease in electrolyte leakage after return to ambient temperature-when CI symptoms appear and when membrane damage is expected to be maximal-is an indication of extensive membrane damage (Bergevin et al., 1993; Côté and Willemot, 1992; Furmanski and Buescher, 


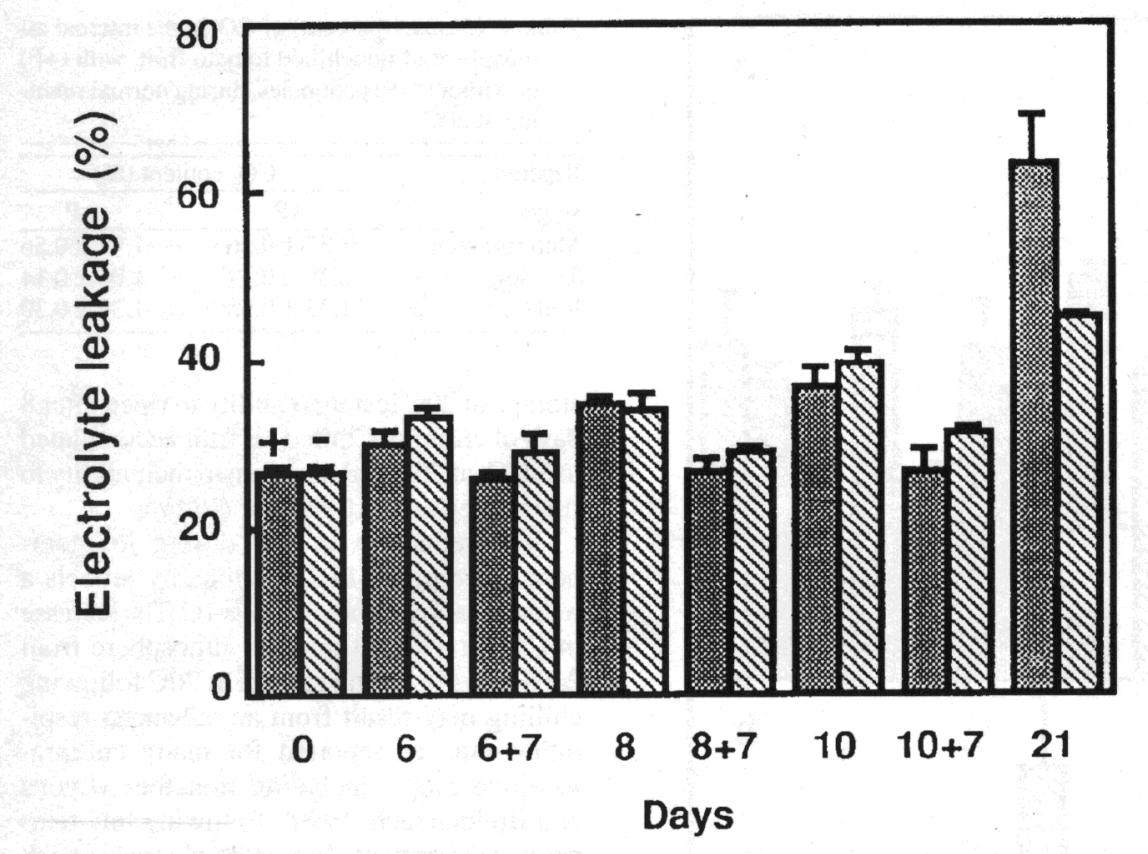

Fig. 2. Electrolyte leakage from pericarp tissue of tomato fruit with (+) or without (-) peduncles. Other details as described for Fig. 1.

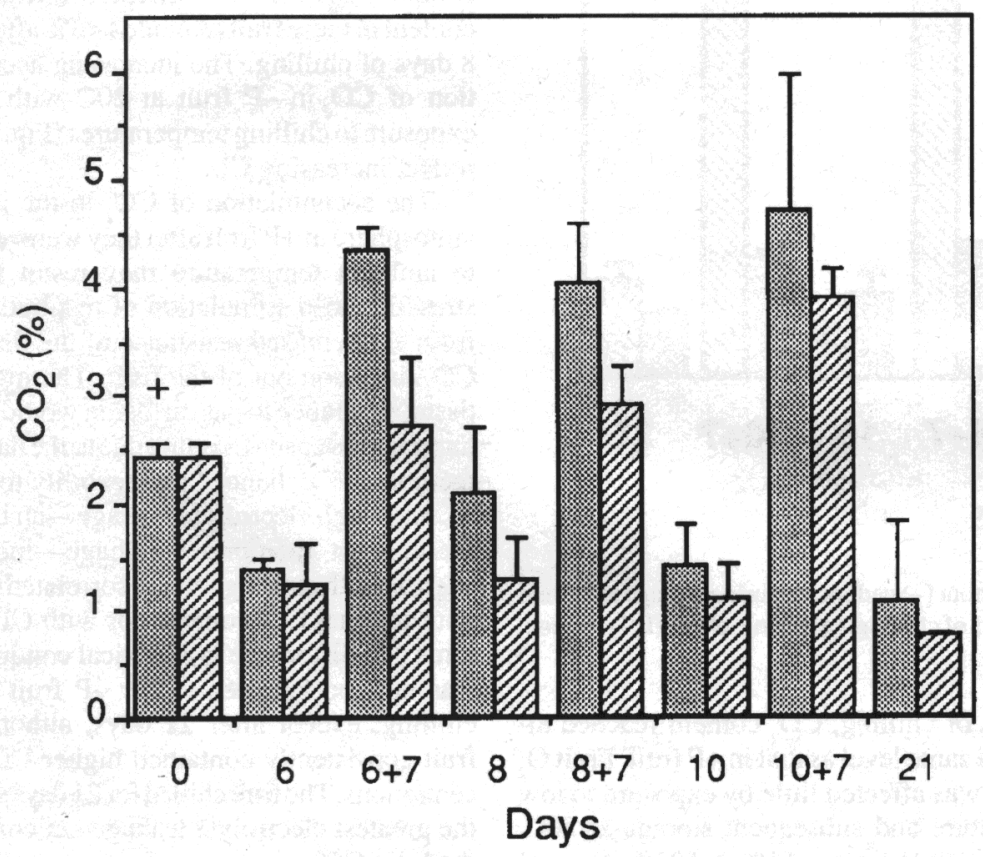

Fig. 3. Internal atmosphere $\mathrm{CO}_{2}$ content of tomato fruit with $(+)$ or without $(-)$ peduncles. Other details as described for Fig. 1.

1979). The return of the conductivity values to prechilling levels in $+\mathrm{P}$ fruit and $\mathrm{CO}_{2}$ accumulation $>4 \%$ were further indications of greater damage to fruit membranes.

The relatively small change in internal atmosphere composition during normal ripening (Table 1) shows that $\mathrm{CO}_{2}$ accumulated in the chilled fruit after they were returned to 20C because of the previous low-temperature treatment, not simply because of the consequence of the climacteric rise in respiration during postchilling ripening.

The results of the present study indicate that the internal atmosphere of chilled tomato temperature stress. CI may then result from prolonged exposure to low-temperature and postchilling high- $\mathrm{CO}_{2}$ stress.

\section{Literature Cited}

Autio, W.R. and W.J. Bramlage. 1986. Chilling sensitivity of tomato fruit in relation to ripening and senescence. J.Amer.Soc.Hort.Sci. 111:201204.

Bergevin, M., G.P. L'Heureux, J.E. Thompson, and C. Willemot. 1993. Effect of chilling and subsequent storage at $20^{\circ} \mathrm{C}$ on electrolyte leakage and phospholipid fatty acid composition of tomato pericarp. Physiol. Plant. 87:(In press).

Bertola, N., A. Chaves, and N.E. Zaritzky. 1990. Diffusion of carbon dioxide in tomato fruits during cold storage in modified atmosphere. Intl. J. Food Sci. \& Technol. 25:318-327.

Brown, E.D., R.Y. Yada, and D.W. Stanley. 1989. Chilling injury and modified atmosphere storage of mature green tomatoes. Can. Inst. Food Sci. Technol. J. 22:339-344.

Buescher, R.W. 1979. Influence of carbon dioxide on postharvest ripening and deterioration of tomatoes. J. Amer. Soc. Hort. Sci. 104:545-547.

Cheng, T.S. and R.L. Shewfelt. 1988. Effect of chilling exposure of tomatoes during subsequent ripening. J. Food Sci. 53: 1160-1162.

Côtê, F. and C. Willemot. 1992. Limitation to the use of electrical conductivity for the measurement of chilling injury in tomato fruit. HortScience 27:651. (Abstr.)

Forney, C.F. and W.J. Lipton. 1990. Influence of controlled atmospheres and packaging on chilling sensitivity, p. 257-267. In: C.Y. Wang (ed.). Chilling injury of horticultural crops, CRC Press, Boca Raton, Fla.

Furmanski, R.J. and R.W. Buescher. 1979. Influence of chilling on electrolyte leakage and internal conductivity of fresh fruits. HortScience 14:167-168.

Geeson, J.D., K.M. Browne, K. Maddison, J. Shepherd, and F. Guaraldi. 1985. Modified atmosphere packaging to extend the shelf life of tomatoes. J. Food Technol. 20:339-349.

Hobson,G.E. 1987.Low-temperature injury and the storage of ripening tomatoes. J. Hort. Sci. 62:5562

Kader, A.A. and L.L. Morris. 1975. Amelioration of chilling injury symptoms on tomato fruits. HortScience 10:324. (Abstr.)

Lyons, J.M. and R.W. Breidenbach. 1990. Relation of chilling stress to respiration, p. 223-233. In: C.Y. Wang (ed.). Chilling injury ofhorticultural crops. CRC Press, Boca Raton, Fla.

Nakhasi, S., D. Schlimme, and T. Solomos. 1991. Storage potential of tomatoes harvested at the breaker stage using modified atmosphere packaging. J. Food Sci. 56:55-59.

Parsons, C.S., R.E. Anderson, and R.W. Penney. 1970. Storage of mature-green tomatoes in controlled atmospheres. J. Amer. Soc. Hort. Sci. 95:791-794.

Salunkhe, D.K. and M.T. Wu. 1973. Effects of low oxygen atmosphere storage on ripening and associatedbiochemical changes of tomato fruits. J. Amer. Soc. Hort. Sci. 98:12-14.

Tomkins, R.G. 1963. The effects of temperature, extent of evaporation and restriction of ventilation on the storage life of tomatoes. J. Hort. Sci. 38:335-347.

U.S. Dept. of Agriculture Marketing Service. 1976. United States standards for grades of fresh tomatoes. Fed. Reg. 41:11464.

Wang, C.Y. 1989. Chilling injury of fruits and vegetables. Food Rev. Intl. 5:209-236. 